\title{
Study on Employees' Turnover in a Human Capital Network
}

\author{
Lirong Deng \\ School of Electrical and Electronic Engineering Department, North China Electric Power University, \\ Baoding 071003, China
}

Keywords: employees' turnover; human capital network; logistic regression; resignation decision model.

\begin{abstract}
This study investigates employees' turnover problems in a human capital network. We take 2015 ICM problem C as an example to form a network in which employees are nodes, and links are relationships of employees in an organization. We model the probability of job hopping as a sigmoid function of a linear combination of satisfaction and relationships with those hopped (logistic regression). By using job hopping probability, we put forward a resignation decision model and design a basic structure of employees' turnover process, setting forth human capital movement mechanisms.
\end{abstract}

\section{Introduction}

Good employee mobility mechanisms are important indicators of the level of talent management for organizations. Market conditions, competitors, the organizations themselves and the organization talented people are changing constantly, thus employee mobility management becomes a deciding factor in the company's future development. According to international human resource authority's demonstration, reasonable flow ability rate of talents should be controlled between $5 \%$ and $10 \%$. For internationally acclaimed companies, this rate is no more than $15 \%$. However, more and more companies have high flow ability rate of talents. When the flow has a poor quality, that is, who the company wants to keep frequently outflows, the flow of talent becomes a talent loss [1].

In this study we investigate employees' turnover problems and build a resignation decision model to estimate and forecast a company's employees churn rate in order to help business managers make decisions. Our paper has three parts. First, we discuss properties of network structure in a network in which employees are nodes, and links are relationships of employees in an organization. Second, we consider combine properties to characterize job hopping probabilities through logistic regression. Third, we build a resignation decision model considering both employees' satisfaction and their ties, which is helpful to improve employee turnover management.

\section{A Network and Its Properties}

For HR management, controlling employee's turnover needs to estimate employees' satisfactions and job-hopping abilities, which requires investigations, evaluations and analysis. March-Simon model [2] tells us whether an employee would decide to takeover or not depends on the reasonableness and ease of the outflow from the enterprise. Employees' satisfactions and relationships with those who have resigned represent their feelings about reasonableness and ease, respectively.

\subsection{Satisfaction.}

Job satisfaction has been a hot issue on organizational behavior. It is the staff attitude to work and an important indicator for employee's enthusiasm. Nowadays, “optimal principle” has gradually been replaced by "principle of satisfaction". Most people make decisions in accordance with their satisfaction, since people are emotional animals [3]. One of the relatively accurate assessments about "satisfaction" is work elements comprehensive evaluation method [4]. It refines the employee satisfaction into multiple dimensions, then divides matters indexes into survey analysis. The results 
are helpful for managers understand the existing problems in the enterprises. At present, international measuring scales are as follows:

Job Descriptive Index;

Minnesota Satisfaction Questionnaire;

Need Satisfaction Questionnaire;

Those questionnaires are analyzing employees’ psychology and giving reasons for their decisions. Factors that influence individual satisfaction are such that income, statues, promotion probability, stabilization and so on. Fig. 3 gives us a diagrammatic sketch to show some important factors [5] describing employees’ satisfaction.

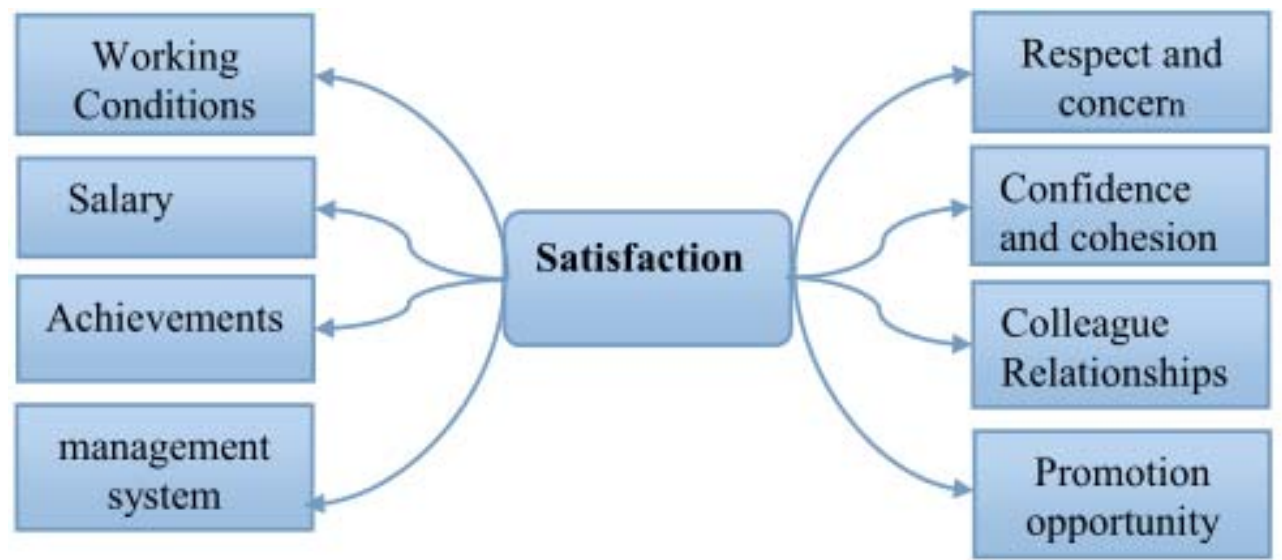

Fig.1 Main factors from employees’ satisfaction questionnaire

\subsection{Relationships with Those Who Have Resigned.}

If one has a low satisfaction with the organization and considers to resign, employees can access information relevant to a transition to other organizations through former colleagues who have already left. For employees, former colleagues who are now working for other organizations are a good source of information. They may ask them about any new opening and their experience in new work condition. These ties tend to be formed between individuals with similar socio-demographic characteristics and may lead to reinforce segregation in the labor market [6]. So network tie is important to observe employees turnover. There are two kinds of ties: one is the same-level tie and the other is superior-subordinate tie [7]. We need to point out that the same level means two employees are in one department, superior-subordinate means their departments have a reporting relationship. When a senior officer has resigned, his authority in staff is a driving force to those who wants to resign. Thus, superior-subordinate tie is often more powerful than the same-level tie. Fig. 2 shows these ties, in which A, B, C, D represent employees. We let $\varphi$ represents ties $(\varphi=1,2)$ and define;

$$
R=\left\{\begin{array}{ll}
0.4 & \varphi=1 \\
0.6 & \varphi=2
\end{array} .\right.
$$

Where $\mathrm{R}$ is relationship.

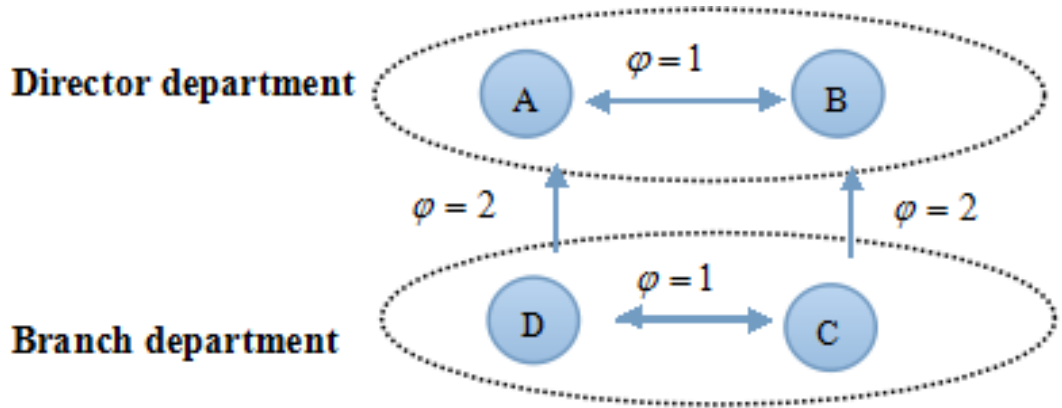

Fig. 2 The same-level tie and superior-subordinate tie in two department. 


\subsection{A Human Capital Network}

Take 2015 ICM problem C as an example, we get a network shown in Fig. 3. Every node is an employee and the node's color means the employee's position. This organization has seven positions. Every cluster represents a department. Links are their superior-subordinate ties (we leave out the same-level ties to make the network clearly. The same-level ties exist in every two nodes in a cluster). A node and a link have properties: satisfaction and relationship, respectively.

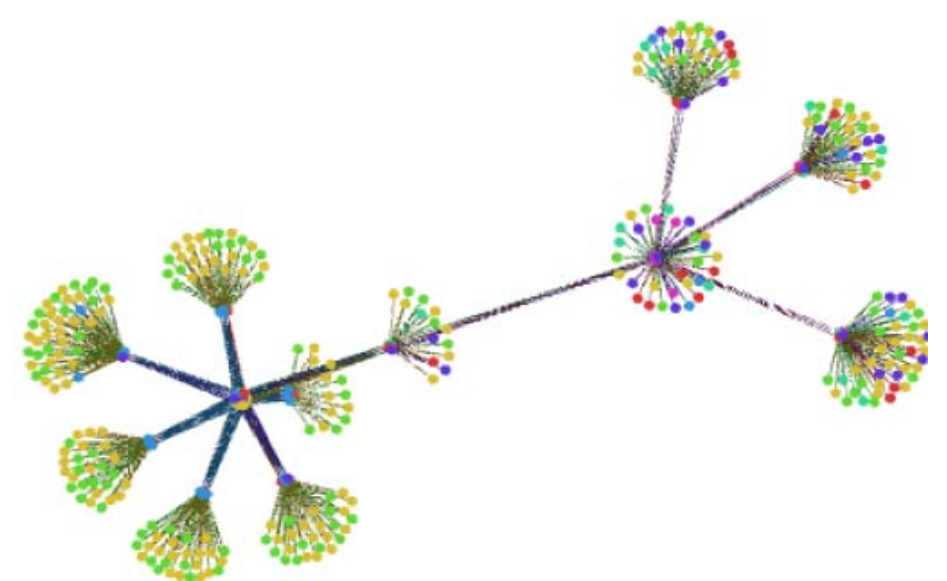

Fig. 3 A human capital network

\section{Model}

\subsection{Job Hopping Probability.}

Our model uses the potential dyads of which the network is comprised. Each observation describes an employee and the outcome variable of interest is coded 1 if someone resigned between time $t$ and $\mathrm{t}+1$, and 0 if that did not happen. We estimate parameters of logistic regression models as follows:

$$
\ln \left(\frac{P_{i t}}{1-P_{i t}}\right)=\alpha S_{i t-1}+\beta R_{i t-1}+\varepsilon \quad P_{i t}=0,1
$$

where $P_{i t}$ is the probability that employee $i$ resigns at time $t ; S_{i t-1}$ is a set of variables measuring satisfaction of $i$ at time $t-1 ; R_{i t-1}$ is a set of variables measuring relationships about employee $\mathrm{i}$ and those who have already hopped at time $t-1 ; \alpha, \beta, \varepsilon$ are constants to be estimated.

We conduct maximum likelihood estimation to calculate these regression variables. The maximum likelihood estimation using expressions of overall density or probability distributions estimates unknown parameters. It transforms the logistic regression problem into solving an objective function, namely the log likelihood function of the extreme value problem. Gradient descent and quasi-Newton method could be adopted to solve the problem.

Taking the past records for samples, we get estimators $\hat{\alpha}, \hat{\beta}, \hat{\varepsilon}$ through SPSS binary regression. If the coefficient of each independent variable is significant, it indicates that the regression model is reliable.

\subsection{Resignation Decision Model.}

The job hopping probability could be written as follows:

$P_{i t}=\frac{1}{1+e^{\alpha S_{i t-1}+\beta R_{i t-1}+\varepsilon}}$

$\alpha, \beta, \varepsilon$ Differs from industries and depends on the human capital assessment of correlation coefficient or assessment rules. Based on this, we build the resignation decision model:

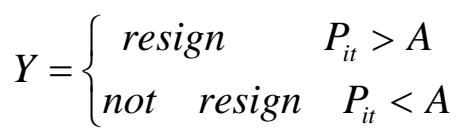


Where A is threshold of job hopping probability. It is from organization's conditions. A is between 0 and 1.

\section{Discussion}

This study examines the social processes that underpin employee's turnover events through logistic regression method. According to our model, whether an employee decide to turnover or not depends on his/her satisfaction and relationships with those hopped. The former represents rationality of outflow while the later represents how easy it is to outflow. As discussed above, we think there are some conclusions worth thinking.

The flow is absolute, and not flow is impossible. The key is whether the flow of human capital is reasonable. When organizations suffer high turnover and don't adopt effective measures, it causes a disorderly state. So organizations must control the human capital flow. Do not let it be a talent loss.

A worker is more likely to churn if he or she was connected to other former employees who have churned. Thus churn seems to diffuse from employee to employee, so identifying those that are likely to churn is valuable information to prevent further churning.

Establishing incentive mechanisms to retain talent. Satisfaction questionnaires help us understand employees’ psychology and reflect company's operating conditions.

Using incentive ways to maximize enthusiasm of the staff, enhancing employee's satisfaction and exploring their own potentials are the focuses of modern human resources management.

\section{References}

[1] Wanyu Zhang. The Research of Talent Loss in Enterprise. MS., Jilin University, China, 2003. p.2.

[2] Xintong Han. Research on Problems and Solutions of Brain Drain of WZ Group. MS., Shandong University, China, 2013. p.45.

[3] Riqi Song. The study of precautions against the knowledge-employee drain in Lukang Group. MS., Beijing Jiaotong University, China, 2007. p.78.

[4] Qipeng Xiao. Research on the Relationship of the Internal Service Quality. MS., Donghua University, China, 2003. p.12.

[5] Information on: http://baike.baidu.com/linkurl=-6EHf1hr4Eqzox7fwrJTzgW4OpaicTzD4fBe kK1uERlf78eyROq_fKoif7KdWOctZE4NRM4zLwDaReCveMQqga

[6] Collet F, Hedström P. Old friends and new acquaintances: Tie formation mechanisms in an interorganizational network generated by employee mobility [J]. Social Networks, 2013, 35(3): 288-299.

[7] Kmec J A. Ties that bind? Race and networks in job turnover [J]. Social Problems, 2007, 54(4): 483-503. 